\title{
Simple and Ultrasensitive Chemically Amplified Electrochemical Detection of Ferrocenemethanol on 4-Nitrophenyl Grafted Glassy Carbon Electrode
}

\author{
Ahyeon Koh ${ }^{1,2 *}$, Junghyun Lee ${ }^{1}$, Jieun Song ${ }^{1}$, and Woonsup Shin ${ }^{1 *}$ \\ ${ }^{1}$ Department of Chemistry and Biomedical Engineering, Sogang University, Seoul 121-742, Republic of Korea \\ ${ }^{2}$ Department of Biomedical Engineering, Binghamton University-State University of New York, 13092 USA
}

\begin{abstract}
Chemically amplified electrochemical detection, redox-active probe being amplified its electrochemical anodic current by a sacrificial electron donor presenting in solution, holds great potential for simple and quantitative bioanalytical analysis. Herein, we report the chemically amplified electrochemical analysis that drastically enhanced a detection of ferrocenemethanol (analyte) by ferrocyanide (chemical amplifier) on 4-nitrophenyl grafted glassy carbon electrodes at $60^{\circ} \mathrm{C}$. The glassy carbon electrode grafted with a 4-nitrophenyl group using an electrochemical reduction suppressed the oxidation of ferrocyanide and thus enabled detection of ferrocenemethanol with excellent selectivity. The ferrocenemethanol was detected down to an $\mathrm{nM}$ range using a linear sweep voltammetry under kinetically optimized conditions. The detection limit was improved by decreasing the concentration of the ferrocyanide and increasing temperature.
\end{abstract}

Keywords : Chemically amplified electrochemical detection, Ferrocenemethanol, Ferrocyanide, Nanomolar electrochemical detection, 4-nitrophenyl grafted glassy carbon electrode

Received October 28, 2016 : Accepted October 29, 2016

\section{Introduction}

In bioanalytical fields, the quantitative analysis methods commonly rely on labeling the biological compound of interest with a fluorophore as a reporter. Despite all benefits of the fluorescence-based methods, this technique is suffered from high-cost due to the complex and expensive optical instrumentation. Alternatively, the electrochemical detection thus draws attention because of the low-cost, fast response, simple design and compact instrumentation that hold a possibility of miniaturization and portability of devices. However, the electrochemical signal from single redox label provides only one or two electrons and the double-layer charging limits the sensitivity of detection. Therefore chemical amplification has studied as a way of enhancing the electrochemical signal and thus

*E-mail address: akoh@binghamton.edu and shinws@sogang.ac.kr DOI: https://doi.org/10.5229/JECST.2016.7.4.286 improving its sensitivity [1-9]. In the chemical amplification, an amplifier-a reagent enabling electron transfer with the oxidized or reduced form of the analytepresents in solution while the reaction is kinetically suppressed or blocked on the electrode surface. Consequently, a redox active compound (i.e., analyte) cycles its electrochemical reaction on the surface of electrode resulting in an increase of local concentration and thus enhancing the sensitivity of detection without affecting on background current.

The chemically amplified electrochemical detection of ferrocene derivatives reported in the aqueous/ organic solvent interface as well as aqueous solution employing an alkanethiol self-assembled monolayer on a gold electrode [10-11]. Signal amplification factors were obtained in several hundred to thousands facilitating a flow injection in a concentration range between $10^{-4}$ and $10^{-7} \mathrm{M}$. A lower detection limit of chemical amplification was studied with tris(2,2'bipyridyl)dichlororuthenium(II) hexahydrate as the 
redox analyte and sodium oxalate as the electron donor on the ITO glass electrodes demonstrating a lower detection limit of approximately $50 \mathrm{nM}$ [9]. However, further improvement is required to achieve real-time electrochemical detection for biological determination.

Herein we report a chemically amplified electrochemical ferrocenemethanol $\left(\mathrm{FcCH}_{2} \mathrm{OH}\right)$ detection system amplified by ferrocyanide $\left(\mathrm{Fe}(\mathrm{CN})_{6}{ }^{4-}\right)$ on the glassy carbon electrode grafted 4-nitrophenyl group. Ferrocenemethanol were detected in an $\mathrm{nM}$ range with good linearity using a linear sweep voltammetry after an optimized the extent of electrode surface modification, temperature, and the concentration of chemical amplifiers, ferrocyanide. This studied detection scheme benefits in the bioanalytical analysis due to the potential of the ferrocenemethanol that easily can be functionalized and linked with a biological analyte (e.g., DNA) with high stability.

\section{Experimental Section}

\subsection{Reagents}

4-Nitrobenzenediazonium tetrafluoroborate, ferrocenemethanol, potassium ferrocyanide were purchased from Sigma-Aldrich. The buffer solution (10 mM Tris-Cl, $45 \mathrm{mM} \mathrm{KCl}, 3.5 \mathrm{mM} \mathrm{MgCl}_{2} ; \mathrm{pH}$ 8.5 adjusted with $1 \mathrm{M} \mathrm{HCl}$ ) was used as an electrolyte solution preparing with distilled/deionized water $(18 \mathrm{M} \Omega / \mathrm{cm})$.

\subsection{Electrochemical instrumentations}

A potentiostat (CHI 900; $\mathrm{CH}$ Instruments, TX) run the cyclic voltammetry employing the electrochemical three-compartment cell consisted of a glassy carbon electrode as a working electrode, a platinum electrode as an auxiliary electrode and an $\mathrm{Ag} / \mathrm{AgCl}(3 \mathrm{M} \mathrm{KCl})$ electrode as references. The glassy carbon disk electrode were made in laboratory using a glassy carbon rod (dia. $1 \mathrm{~mm}$; Hochtemperatur-Werkstoffe $\mathrm{GmbH}$ ) or purchased from BAS (dia. $3 \mathrm{~mm}$ ). The electrodes were prepared by polishing with a 0.3 micron and 0.05 micron alpha alumina (Buehler) on a polishing cloth (NANOCLOTH ${ }^{\circledR}$, Buhler) and sonicated in $50 \%$ ethanol solution for five minutes followed by rinsing with deionized water (Millipore).

\subsection{Modification glassy carbon electrode with 4- nitrobenzenediazonium tetrafluoroborate}

Chronoamperometry carried out electrochemical modification of the glassy carbon electrode in in an acetonitrile solution containing $10 \mathrm{mM} 4$ nitrobenzenediazonium tetrafluoroborate and $0.1 \mathrm{M}$ tetrabutylamine hexafluorophosphorous $\left(\mathrm{TBAPF}_{6}\right.$ ) at $-1.0 \mathrm{~V}$ vs. $\mathrm{Ag} / \mathrm{AgCl}$. The 4-nitrophenyl modified electrodes were washed by rinsing with water and ultrasonicating for 5 minutes. Cyclic voltammetry confirmed the extent of the modification either in $1 \mathrm{mM}$ ferrocyanide or ferrocenemethanol solution.

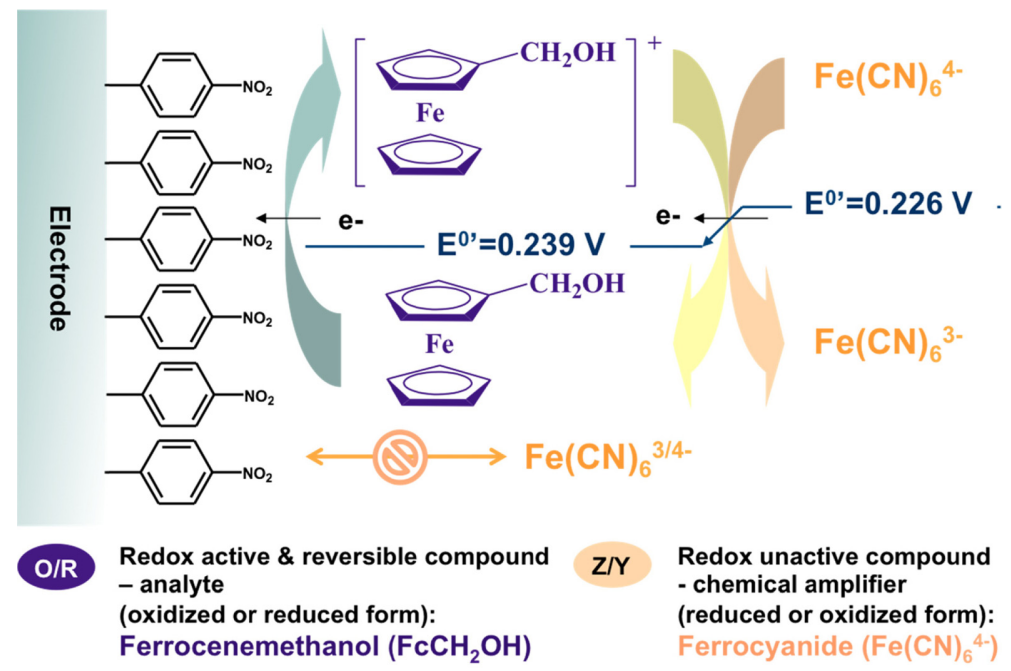

Scheme 1. The chemically amplified electrochemical detection system using a 4-nitrophenyl grafted electrode. 


\section{Results and Discussion}

3.1. Preparation and characterization of 4-nitrobenzene modified glassy carbon electrode for chemically amplified electrochemical detection

The glassy carbon electrode grafted 4-nitrophenyl group provides selective electron transfer in a chemically amplified electrochemical detection system between the redox analyte and the chemical amplifier (Scheme 1). The grafted surface allowed for relatively facile electrochemical oxidation of the analyte, ferrocenemethanol, but inhibited a background current from the electron donor, ferrocyanide. The electrodes modified with diazonium salt using a chronoamperometry serve as great barrier layers to differentiate the electrochemical reaction [12-16]. This surface modification steps involve the formation of a diazonium radical, followed by the formation of a covalent bond to the glassy carbon

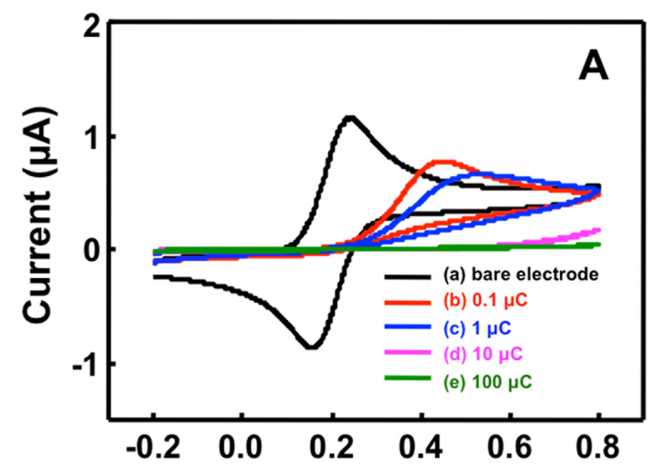

Potential (V vs. Ag/AgCl)

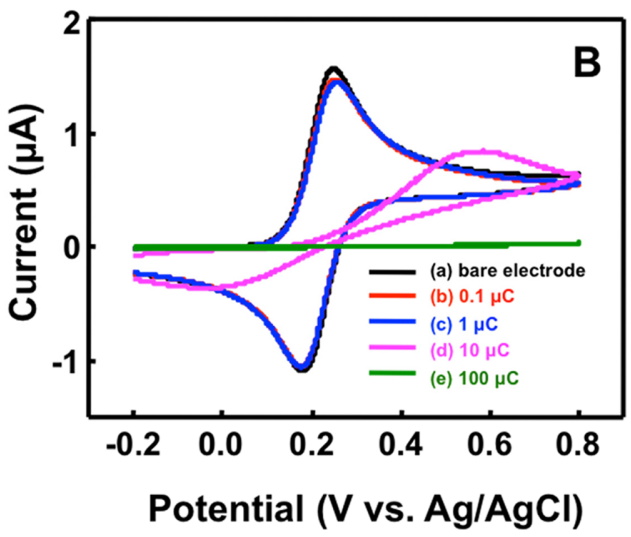

Fig. 1. Cyclic voltammograms of (A) ferrocyanide and (B) ferrocenemethanol in buffer solution evaluating with (a) a bare electrode and modified electrode by reducing 4-nitrobenzenediazonium tetrafluoroborate with (b) 0.1 , (c) 1 , (d) 10, and (e) $100 \mu \mathrm{C}$ charge. The scan rate was $50 \mathrm{mV} / \mathrm{s}$ at RT. electrode [12]. Therefore, the charge of diazonium reduction enables to control an extent of modification. Charges of $0.1-1 \mu \mathrm{C}$ resulted in the modified electrode behaving electro-active to ferrocenemethanol and inhibited current in ferrocyanide. However, more than $10 \mu \mathrm{C}$ reduction charge resulted over modification and thus blocked redox current of ferrocenemethanol as well as ferrocyanide (Fig. 1). Additionally, the extent of modification can be further optimized not only as a function of the reducing charge but also the concentration of diazonium solution and the reducing time and electrode potential [15]. Indeed, optimum charge (i.e., $2 \mu \mathrm{C}$ ) was found to exhibit the hydrophilic/hydrophobic interaction so that it blocked ferrocyanide but ferrocenemethanol, while modified with a $1 \mathrm{~mm}$ diameter glassy carbon electrode in $10 \mathrm{mM}$ 4-nitrobenzenediazonium tetrafluoroborate and $0.1 \mathrm{M}$ tetrabutylamine hexafluorophosphorous $\left(\mathrm{TBAPF}_{6}\right)$ as an electrolyte in acetonitrile at $-1.0 \mathrm{~V}$ vs. $\mathrm{Ag} / \mathrm{AgCl}$. As shown in Fig. 2, the resulted electrode inhibited anodic current of ferrocyanide at $+0.3 \mathrm{~V}$ but
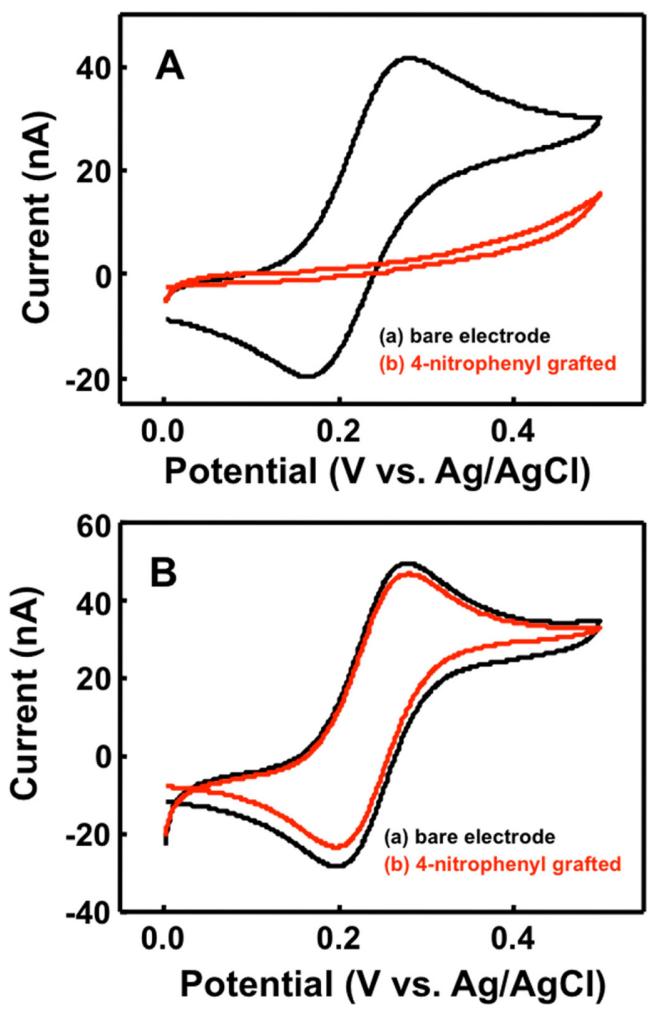

Fig. 2. Cyclic voltammograms of (a) bare and (b) 4nitrophenyl grafted glassy carbon electrode in $1 \mathrm{mM}$ (A) potassium ferrocyanide and (B) ferrocenemethanol in a buffer solution at $5 \mathrm{mV} / \mathrm{s}$ of scan rate at RT. 
barely affected electron transfer of ferrocenemethanol (target analyte) exhibiting electrochemical reaction as same as the bare electrode. Of note, the 4-nitrophenyl grafted electrode exploited selectivity to suppress the direct oxidation of ferrocyanide (hydrophilic) due to the hydrophobic surface character, thereby enabling the signal amplification scheme for ferrocenemethanol (slightly hydrophobic) detection [13].

3.2. Chemical amplification of ferrocenemethanol, redox active analyte by ferrocyanide and ferricyanide as amplifiers

To be suitable for chemically amplified electrochemical detections, the electrode must enable a fast
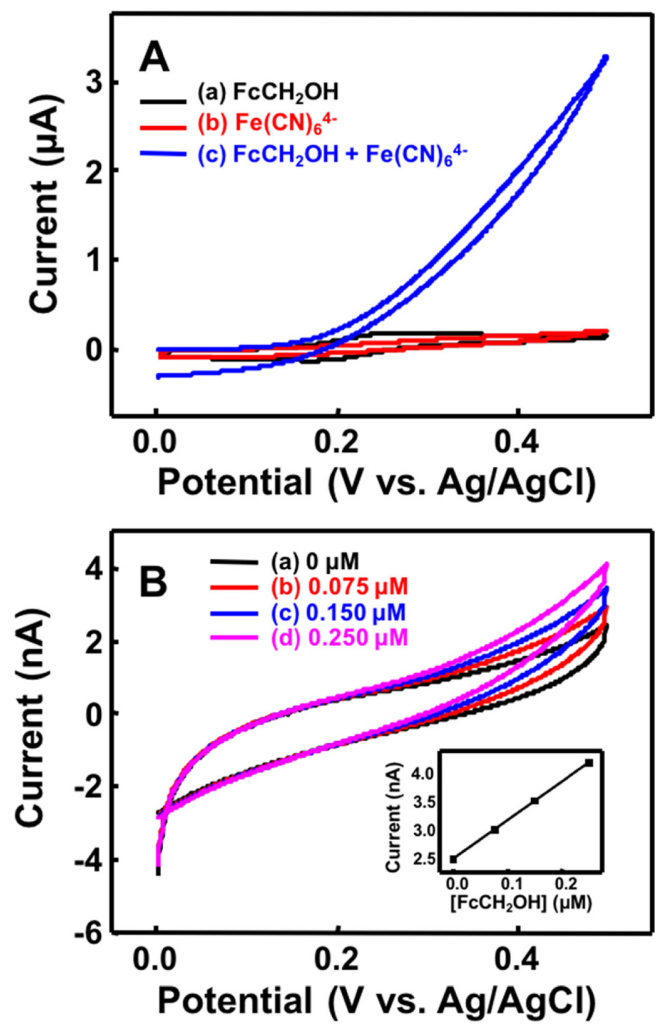

Fig. 3. (A) Cyclic voltammograms of $0.1 \mathrm{mM}$ ferrocenemethanol in buffer solution (a) without and (c) with $10 \mathrm{mM}$ ferrocyanide. (b) Cyclic voltammograms of $10 \mathrm{mM}$ ferrocyanide in a reaction buffer in the absence of ferrocenemethanol. All cyclic voltammograms were collected with 4-nitrobenzendiazonium modified glassy carbon electrode as a working electrode. The scan rate was $50 \mathrm{mV} / \mathrm{s}$ at RT. (B) Cyclic voltammogram of various concentrations of ferrocenemethanol: (a) 0 , (b) 0.075 , (c) 0.150 , and (d) $0.250 \mu \mathrm{M}$ with $0.1 \mathrm{mM}$ ferrocyanide. Insert plot indicates the calibration curve. The scan rate was $5 \mathrm{mV} / \mathrm{s}$ run at RT. electron exchange with the redox analyte, but perform negligible electrochemical reactions with the electron donor (i.e., amplifier) [9]. The 4-nitrophenyl grafted glassy carbon electrode described above detected amplified anodic currents of ferrocenemethanol in the presence of ferrocyanide in an aqueous solution as an amplifier (Fig. 3). On this chemically amplified electrochemical detection mechanism, ferrocenemethanol has fast electrochemical reactions on modified electrode surfaces as well as fast electron transfer rate with ferrocyanide allowing the application of the EC' mechanism [17].

In the absence of ferrocyanide, cyclic voltammetry of $0.1 \mathrm{mM}$ ferrocenemethanol displayed well-defined reversible oxidation and reduction peaks showing in Fig. 3A (a). After addition of $10 \mathrm{mM}$ ferrocyanide, the anodic current increased considerably expressing a catalytic current (Fig. 3A (c)). The electro-catalytic reaction between ferrocenemethanol and ferrocyanide defined as the following [11]:

$$
\begin{aligned}
& \mathrm{FcCH}_{2} \mathrm{OH}+\mathrm{e}^{-} \rightarrow \mathrm{FcCH}_{2} \mathrm{OH}^{+} \\
& \mathrm{FcCH}_{2} \mathrm{OH}^{+}+\mathrm{Fe}(\mathrm{CN})_{6}{ }^{4-} \rightarrow \mathrm{FcCH}_{2} \mathrm{OH}+\mathrm{Fe}(\mathrm{CN})_{6}{ }^{3-}
\end{aligned}
$$

The ferrocenemethanol enabled to be detected in a sub-micromolar concentration range in the presence of ferrocyanide with good linearity at room temperature since ferrocyanide acts as an electron donor to amplify the electrochemical current of ferrocementhanol (Fig. 3B). The similar electrode potential of ferrocyanide and ferrocenemethanol (less than $10 \mathrm{mV}$ apart), thermoneutral character, and rapid electron self-exchange rate constants allow desirable electron transfer and thus make this pair of reactants suitable for a chemically amplified electrochemical detection scheme [18-21].

\subsection{Kinetics for electrochemical sensing in $\mathrm{nM}$ range}

The chemically amplified electrochemical detection system rely on EC' mechanism especially the catalytic reaction, $\mathrm{E}_{\mathrm{r}} \mathrm{C}^{\prime}{ }_{\mathrm{i}}$. The catalytic current increased as increase concentration of ferrocyanide and saturated at the level of hundred times larger than ferrocenemethanol (Fig. 4). According to $\mathrm{E}_{\mathrm{r}} \mathrm{C}^{\prime}{ }_{\mathrm{i}}$ mechanism, the rate constant of the amplification of ferrocenemethanol by ferrocyanide can be determined by equation (1), where $i_{\infty}$ is limiting value of catalytic current; $C_{O}{ }^{*}$ and $C_{Z}{ }^{*}$ are concentration of ferrocenemethanol and ferrocyanide, respectively; $k^{\prime}$ is rate constant for chemical amplification reaction; $n$ is 

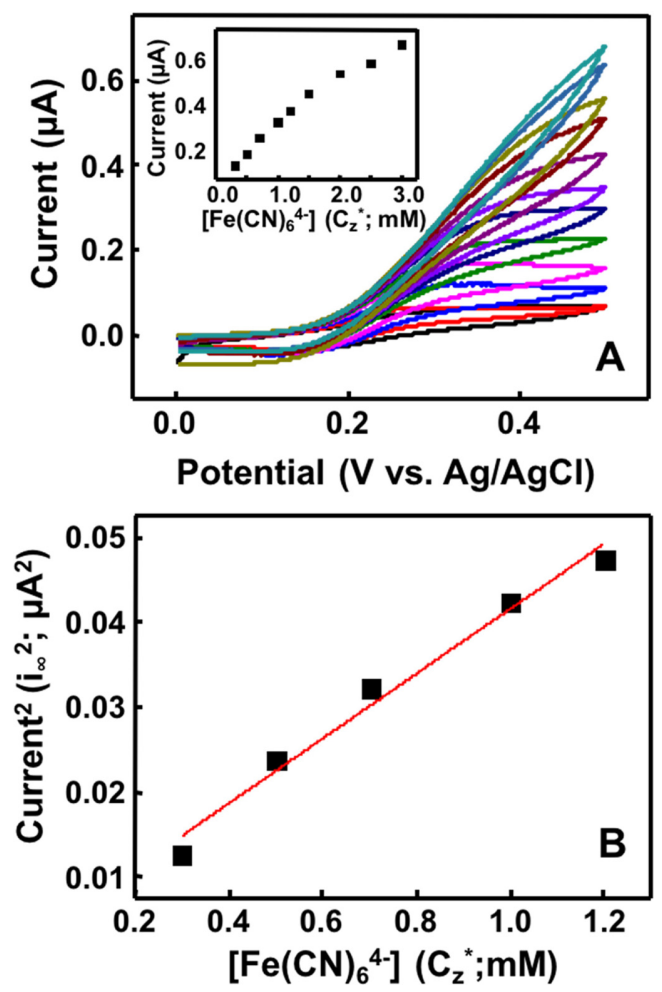

Fig. 4. (A) Cyclic voltammograms of $10 \mu \mathrm{M}$ ferrocenemethanol in the presence of different concentrations of ferrocyanide $\left(\left[\mathrm{Fe}(\mathrm{CN})_{6}{ }^{4-}\right]\right.$ : from $0 \mathrm{mM}$ to $\left.3.5 \mathrm{mM}\right)$ in a buffer solution at a scan rate of $5 \mathrm{mV} / \mathrm{s}$. Insert plot indicates the $i_{\text {pa }} v s$. $\left[\mathrm{Fe}(\mathrm{CN})_{6}{ }^{4-}\right]$. (B) The $\mathrm{i}_{\mathrm{pa}}{ }^{2}$ vs. $\left[\mathrm{Fe}(\mathrm{CN})_{6}{ }^{4-}\right]$ plot to determine rate constant of amplification.

number of electrons involved; $F$ is the Faraday constant; A is electrode surface area; and $D$ is diffusion coefficient of ferrocyanide [17].

$$
i_{\infty}=n F A C_{o} *\left(D k^{\prime} C_{z}^{*}\right)^{1 / 2}
$$

The rate constant of the amplification $\left(k^{\prime}\right)$ was calculated by the slope of the plot of the oxidation current at $0.5 \mathrm{~V}$ as a function of the square concentration of the chemical amplifier (Fig. 4B). The rate constant of amplification between ferrocenemethanol and ferrocyanide $\left(k^{\prime}\right)$ was determined as $3.81 \times 10^{-2} \mathrm{M}^{-1} \mathrm{~s}^{-1}$.

Ferrocenemethanol detection was studied at various temperatures for sub-nM determination (Fig. 5). The efficiency of detection $(\Delta \mathrm{I}$; the current difference between 0 and $600 \mathrm{nM}$ of $\mathrm{FcCH}_{2} \mathrm{OH}$ ) was exponentially increased by increasing temperature as showing in Fig. 5B. The improvement of kinetics between ferrocenemethanol and ferrocyanide yield this sensitivity
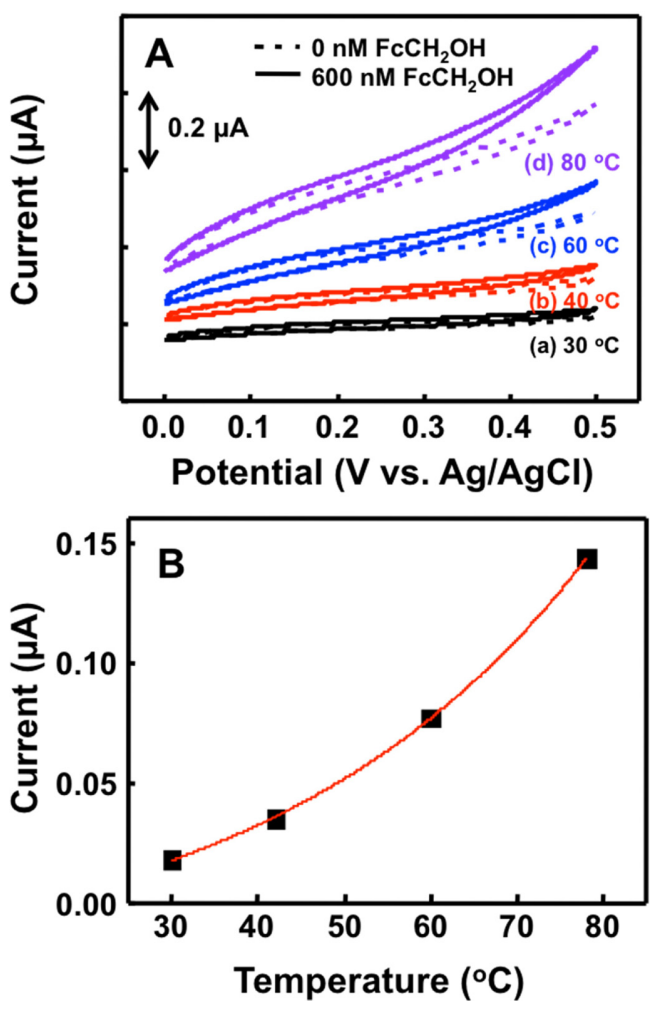

Fig. 5. (A) Cyclic voltammograms of ferrocenemethanol at the concentration of 0 and $600 \mathrm{nM}$ with $0.1 \mathrm{mM}$ ferrocyanide at various temperatures: (a) 30, (b) 40 , (c) 60 , and (d) $80^{\circ} \mathrm{C}$. (B) The plot of difference of current between 0 and $600 \mathrm{nM}$ as a function of temperature.

increase. The potential of ferrocyanide shifted negatively by a temperature coefficient of $-1.3 \mathrm{mV} /{ }^{\circ} \mathrm{C}[22-$ 23 ], resulting the electron transfer to ferrocenemethanol easier while the electrochemical character of ferrocenemethanol kept constant independent of temperature increase. Of note, the efficacy of blocking ferrocyanide on the modified electrode surface did not change by the temperature being increased.

\subsection{Electrochemical sensing in $\mathrm{nM}$ range by chemical amplification}

The chemically amplified electrochemical detection of ferrocenemethanol carried out in the nanomolar range according to the optimized criteria described above. The ferrocyanide-amplified electrochemical detection of dissolved ferrocenemethanol was dramatically increased at $60^{\circ} \mathrm{C}$ compared to the results at room temperature. In addition to the elevation of temperature, decreasing the concentration of ferrocy- 

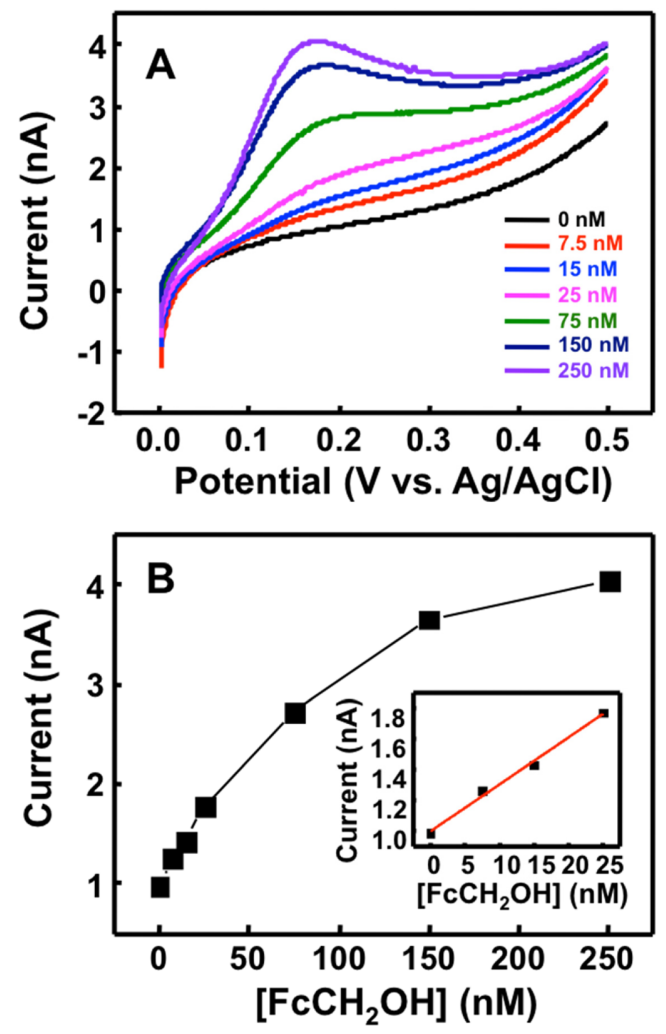

Fig. 6. (A) Linear sweep cyclic voltammograms of ferrocenemethanol from 7.5 to $250 \mathrm{nM}$ with $10 \mu \mathrm{M}$ ferrocyanide as a chemical amplifier at the scan rate of $5 \mathrm{mV} / \mathrm{s}$, and the temperature was $60^{\circ} \mathrm{C}$. (B) Calibration curve constructed with determined current at $0.180 \mathrm{~V}$ (vs. $\mathrm{Ag} / \mathrm{AgCl}$ ). Inset indicates the focused plot for low-range concentrations of ferrocenemethanol.

anide granted to detect extremely low concentrations of ferrocenemethanol at $60^{\circ} \mathrm{C}$ (Fig. 6). However, in the case with less amount of chemical amplifier, the high concentration detection was saturated (Fig. 6B). Approximately hundred times higher concentration of the amplifier than the concentration of electroactive analyte were suitable for greatest detection efficacy in this system. Indeed, limit of detection of $5 \mathrm{nM}$ was achieved by optimizing kinetics of electron transfer and interaction of amplifier on the electrode surface by electrochemically modified glassy carbon electrode based on chemically amplified electrochemical detection.

\section{Conclusions}

The combination of ferrocenemethanol (electro- chemically active analyte), ferrocyanide, (sacrificial electron donor and chemical amplifier) and the 4-nitrophenyl grafted glassy carbon electrode provide a fundamental basis demonstrating chemically amplified electrochemical analysis. The extent of 4-nitrophenyl functions on the electrode surface was optimized to react with ferrocenemethanol but ferrocyanide by controlling the reduction charge of diazonium. The detection of solution-phase ferrocenemethanol by cyclic voltammetry and linear voltammetry showed excellent sensitivity and linearity. As increasing temperature, the electrode potential of ferrocyanide negatively shifts and thus drives the electron flow more favorably. Additionally, optimized the concentration of the chemical amplifier, hundred times more than the concentration of the redox analyte, make it possible to detect extremely low concentrations such as $5 \mathrm{nM}$.

Ferrocenemethanol derivatives with carboxylate or amine functional groups enabling to tether with biological molecules such as DNA and proteins can be synthesized and therefore have wide application potential as an electrochemical tag in biological detections. Additionally, ferrocenemethanol and ferrocyanide are chemically stable, relatively small molecule, and low cost. Various electrochemical detection methods (e.g., differential pulse voltammetry) may further result in improvement of detection while applying this detection scheme in complex biological solutions. Indeed, the chemically amplified electrochemical detection system studied here will be an attractive technique in biological detection systems.

\section{Acknowledgment}

This research was supported by the Next-generation Medical Device Development Program for Newly-Created Market of the National Research Foundation (NRF) funded by the Korean government, MSIP (No. 2015M3D5A1065760).

\section{References}

[1] A. P. Doherty, M. A. Stanley, D. Leech and J. G. Vos, Anal. Chim. Acta, 1996, 319(1), 111-120.

[2] T. Yao, S. Suzuki, T. Nakahara and H. Nishino, Talanta, 1998, 45(5), 917-923.

[3] S. Cosnier, C. Gondran, J.-C. Watelet, W. D. Giovani, R. P. M. Furriel and F. A. Leone, Anal. Chem., 1998, 70(18), 3952-3956. 
[4] T. J. Moore, M. J. Joseph, B. W. Allen and L. A. Coury, Anal. Chem., 1995, 67(11), 1896-1902.

[5] K. B. Male, P. O. Gartu, A. A. Kamen and J. H. T. Luong, Biotechnol. Bioeng., 1997, 55(3), 497-504.

[6] C. G. Bauer, A. V. Eremenko, E. Ehrentreich-Forster, F. F. Bier, A. Makower, H. B. Halsall, W. R. Heineman and F. W. Scheller, Anal. Chem., 1996, 68(15), 24532458.

[7] E. Katz and I. Willner, J. Electroanal. Chem., 1996, 418(1), 67-72.

[8] D. J. Caruana and A. Heller, J. Am. Chem. Soc., 1999, 121(4), 769-774.

[9] D. Zheng, N. Wang, F.-Q. Wang, D. Dong, Y.-G. Li, X.Q. Yang, L.-H. Guo and J. Cheng, Anal. Chim. Acta, 2004, 508(2), 225-231.

[10] C. Shi and F. C. Anson, J. Phys. Chem. B, 1998, 102(49), 9850-9854.

[11] P. T. Radford, M. French, and S. E. Creager, Anal. Chem., 1999, 71(22), 5101-5108.

[12] P. Allongue, M. Delamar, B. Desbat, O. Fagebaume, R.Hitomi, J. Pinson and J.-M. Save'ant, J. Am. Chem. Soc., 1997, 119(1), 201-207.

[13] C. Saby, B. Ortiz, G. Y. Champagne and D. Be'langer,
Langmuir, 1997, 13(25), 6805-6813.

[14] M. D"Amours and D. Be'langer, J. Phys. Chem. B, 2003, 107(20), 4811-4817.

[15] S. Baranton and D. Be'langer, J. Phys. Chem. B, 2005, 109(51), 24401-24410

[16] G. Liu, J. Liu, T. Böcking, P. K. Eggers and J. J. Gooding, Chem. Phys., 2005, 319(1), 136-146.

[17] A. J. Bard and L. R. Faulkner, Electrochemical methods-Fundametals and applications. second ed.; John Wiley \& Sons. Inc.: p 501 (2001).

[18] G. E. McManis, R. M. Nielson, A. Gochev and M. J. Weaver, J. Am. Chem. Soc., 1989, 111(15), 5533-5541.

[19] R. M. Nielson, G. E. McManis, L. K. Safford and M. J. Weaver, J. Phys. Chem., 1989, 93(5), 2152-2157.

[20] E. S. Yang, M.-S. Chan and A. C. Wahl, J. Phys. Chem., 1975, 79(19), 2049-2052.

[21] E. S. Yang, M.-S. Chan and A. C. Wahl, A. C. J. Phys. Chem. B, 1980, 84(23), 3094-3099.

[22] A. Olivier, E. Merienne, J. P. Chopart and O. Aaboubi, Electrochim. Acta. 1992, 37(11), 1945-1950.

[23] T. Vos, P. Grundler, A. Kirbs and G.-U. Flechsig, Electrochem. Commun., 1999, 1(9), 383-388. 